\title{
BEHAVIOUR OF RESTRAINED STEEL BEAM AT ELEVATED TEMPERATURE - PARAMETRIC STUDIES
}

\author{
Ahmed Allam ${ }^{\mathrm{a}}$, Ayman Nassif ${ }^{\mathrm{b}}$, Ali Nadjaic, \\ a Cundall, One Carter Lane, London EC4V 5ER, UK \\ ${ }^{\mathrm{b}}$ School of Civil Engineering and Surveying, University of Portsmouth, Portsmouth PO1 3AH, UK \\ ${ }^{c}$ Department of Built Environment, FireSERT, Ulster University UK
}

\begin{abstract}
This paper presents the study for investigating computationally and analytically how different levels of restraint from surrounding structure, via catenary action in beams; affect the survival of steel framed structures in fire. This study focuses on examining the mid-span deflection and the tensile axial force of a non-composite heated steel beam at large deflection that is induced by the catenary action during exposure to fires. The study also considers the effect of the axial horizontal restraints, load-ratio, beam temperature gradient and the span/depth ratio. It was found that these factors influence the heated steel beam within steel construction and its catenary action at large deflection. The study suggests that this may help the beam to hang to the surrounding cold structure and delays the run-away deflection when the tensile axial force of the beam has been overcome. While that the tensile axial force at large deflection can lead to integrity failure and consequent fire spread, however, it may be possible to achieve much greater real fire resistance when sufficient strength and ductility are designed into key structural elements. The nature of this phenomenon has been investigated in a joint project between the University of Sheffield where the numerical analysis has been carried out at the time of the project, and the University of Manchester where the furnace tests were conducted. This paper is part one of the parametric study and it discusses both the effect of the axial horizontal restraints and load-ratio on the heated steel-beam. Reliance on the prescriptive standard fire solutions may lead to an unpredicted behaviour of the structure members if the impact of potential real fires is not considered.
\end{abstract}


Behaviour of Restrained Steel Beam at elevated temperature - Parametric Studies

\section{INTRODUCTION}

In recent years, steel-framed construction has become very popular for commercial buildings in Britain, largely because of faster construction times compared to other systems. Composite steel-concrete construction has been an important factor, offering significant savings in material compared with non-composite frames by taking advantage of the composite action which is achieved by connecting the concrete slab to the steel-section using shear connectors. However, non-composite steel structures have other advantages which make it attractive to use non-composite sections compared with many other construction methods. Precast concrete has proved a definite success where structures are erected from prefabricated flooring units in combination with steel frames. The fact that no connection is required between the precast concrete slab and the steel beam gives the steel beam the flexibility to act separately from the slab, taking into consideration the fire protection which is provided to the top flange of the steel beam by the supported concrete.

To prevent the premature failure of a structure in fire, the UK building Regulations require the load-bearing elements of the structure to have a minimum standard of fire resistance. The fire resistance of a load-bearing member is a measure of its survival time in fire conditions before losing its load-carrying capacity. The assessment of the resistance of these steel framed structure members in fire continues to be based upon the performance of isolated elements in standard furnace tests. The study presented in this paper encourages the approach adopted by BS 9999:2008 as the fire safety code of practice for building design, management and use. The standard outlines ways to meet fire safety legislation through a more flexible approach to design. BS 9999 replaces DD 9999:2005 which is the code of practice for fire safety in the design, construction and use of buildings. Further design guidance document that support the practice of this field in the industry is the Fire Safe Design: A New Approach to Multi-Storey Steel-Framed Buildings; SCI Publication P288 since 2000 and CEN. EN 1991: Eurocode 1: Basis of design and actions on structures. EN 1991-1-2, General actions - actions on structures exposed to fire 2002.

Because of the restrictive cost of carrying-out real fire tests on full-scale structures on the one hand, and computational advances in structural analysis on the other, numerical and analytical methods are now becoming accepted as alternatives for determining the behaviour of structures in fire. Analytical methods should provide as accurate a prediction as possible by taking into consideration the factors governing the behaviour of the steel elements in fire. 
However, numerical methods, using the cutting-edge technology of computer modelling, tend to increase the capability of simulating structural behaviour in fire modelling the precise structural details [1]. Therefore, it is favourable to consider the response of full frames or subframe rather than simply analysing isolated members [2].

In a recent work, the large deflection behaviours of axially restrained corrugated web steel beam (CWSB) at elevated temperatures were investigated using a finite element method [3]. Parameters that greatly affected behaviours of CWSB at elevated temperatures were the load ratio, the axial restraint stiffness ratio, and the span-depth ratio. Other work included numerical studies on large deflection behaviours of restrained castellated steel beams in a fire where the impact of the catenary action is considered [4]. The impact of the induced axial forces in the steel beam during cooling stage of a fire when the beam temperature decreases, if thermal shortening of the beam is restrained, large tensile forces may be induced in the beam $[5,6]$. A performance-based approach is developed for assessing the fire resistance of restrained beams. The approach is based on equilibrium and compatibility principles, takes in to consideration the influence of many factors including fire scenario, end restraints, thermal gradient, load level and failure criteria in evaluating fire resistance $[7,8]$.

\section{TEST SETUP AND COMPUTER MODELLING}

The experimental facilities at the University of Manchester provide a good opportunity for researchers to study experimentally the actual behaviour of connected members in fire conditions. This should assist in developing and further improving the existing computer models which have the capability of predicting accurately the frame response, through investigating different structural and fire scenarios. Moreover, such tests form an important source of data for validating the results obtained from numerical models. Moreover, such tests can allow designers to review and refine existing design guidelines, which were largely developed on the basis of large numbers of isolated member tests, and to develop new design guides based on observed structural behaviour.

In the test programme the beam was mainly unprotected, although the amounts of insulation were varied, including the case in which the web and the lower flange were exposed and the upper flange was fully protected. The columns were generally fire-protected and were reused for a series of tests. The beam and column profiles in the region of the connection were normally protected. The top flange of the beam was protected by insulation. The beam size 
was $178 \times 102 \times 19$ UB and the column $152 \times 152 \times 30 \mathrm{UC}$, both in S275 steel. The columns were secured in position at their top and bottom using roller bearings to give a pinned condition at their supports. The surrounding reaction frame consisted of two $203 \times 203 \times 60 \mathrm{UC}$ sections at the sides connected to pairs of $432 \times 100$ channels at the top and bottom.

Fig. 1 shows the element layout of the numerical model used to simulate the test set-up. The complete assembly and its details have been discussed in a former paper [9] as well as in the first author's PhD thesis [10]. The finite element program VULCAN used in the analysis is based on a line element which is geometrically highly non-linear, and allows material nonlinearity. Because of the inherently non-linear nature of the problem the solution procedures are highly iterative. The details of the formulation of these elements and the different material constitutive modelling at elevated temperatures have been explained in many references [10].

The beam-columns are represented by arrays of 2-noded line elements which are used to simulate the two internal columns, the reaction frame and the heated beam. The effect of the additional axial stiffness at both ends of the heated beam was represented by using pinned spring elements with the specified value of the axial stiffness provided during the test. To model the characteristics of steelwork connections two-nodded spring elements of zero length were used, with the same nodal degrees of freedom as the beam-column elements. The moment-rotation characteristics of these elements were obtained from test results at ambient temperature, degrading according to the EC3 elevated-temperature strength reduction factors.

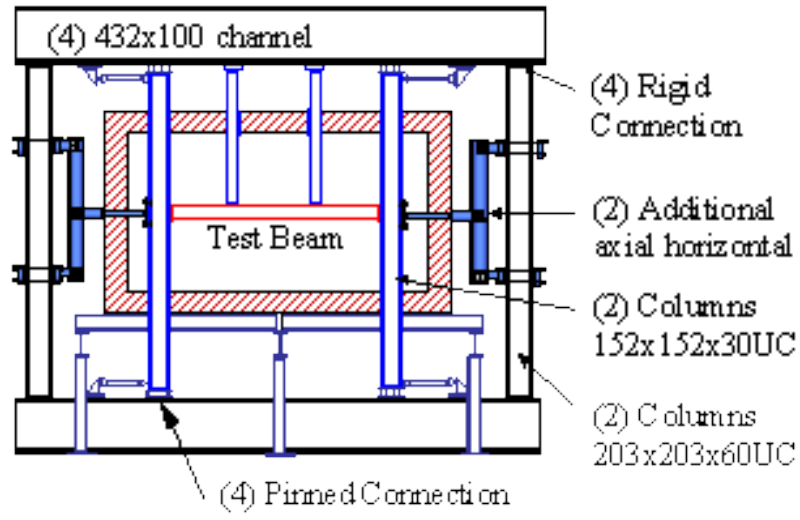

(a) General view of test arrangement.

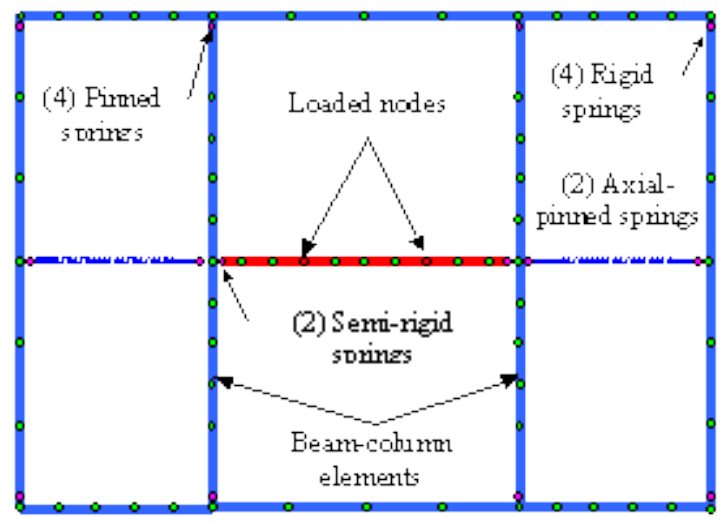

(b) Computer modelling

Fig. 1 General principles of test and modelling. 
Little previous test data existed on the effect of degree of restraint on the performance of heated beams. It was therefore important to check that the software could model this satisfactorily, before embarking on a more comprehensive analytical parametric study. Typical comparisons for mid-span deflection and axial force of the heated beam, which were used in validating VULCAN against test results, are shown in Fig. 2. It is important to note that the experimental data shown in Fig. 2 were preliminary results. While the initial experiments were stopped as the beam deflection meets the failure definition by the standard code before the development of the tensile axial forces in the heated beams, the numerical analysis was utilised to demonstrate the potential of developing the catenary action at a later stage of the fire exposure. It is noteworthy that the fire test was stopped before the development of the tensile axial forces because the standard deflection criterion was met during the fire test. In spite of the complexity in carrying out transient thermo-mechanical simulation on structural assemblies, Fig. 2 shows good agreement between the experimental measurements and the thermos-mechanical Finite Element numerical model. For example, the deflection of the restraint steel beam with a load-ratio of 0.2 during the fire exposure, was measure as $50 \mathrm{~mm}$ when the bottom flange temperature reached $840 \mathrm{C}$. The predicted value of the deflection, from the numerical thermos-mechanical model, was $50 \mathrm{~mm}$ at about $870 \mathrm{C}$. Similar agreement between the test results and the numerical model was established in relation to the diminishing compressive force developed in the restraint beam after exposure of the bottom flange to temperature higher than about $700 \mathrm{C}$ which is associated with rapid increase in the central deflection. It is unfortunate that the fire test was stopped when the deflection criterion was reached which resulted in lack of experimental data to evidence the development of tensile catenary forces but there is strong indication form the validated numerical model that the axial compression diminishes to zero at $900 \mathrm{C}$ and tensile axial forces develop instead reaching $25 \mathrm{kN}$ at $1000 \mathrm{C}$, for the tested beam with $\mathrm{LR}=0.2$ as shown in Fig. 2. The sign convention for the axial forces adopted for the purpose of this paper is that compressive forces are positive while tensile forces are negative. It is noteworthy that the effect of the induced axial tensile forces on the end connection was not part of the investigation reported here. Other work was produced by other research groups addressing this point in great details. Currently, the code of practice requires protection of all connections. [11] 
Behaviour of Restrained Steel Beam at elevated temperature - Parametric Studies

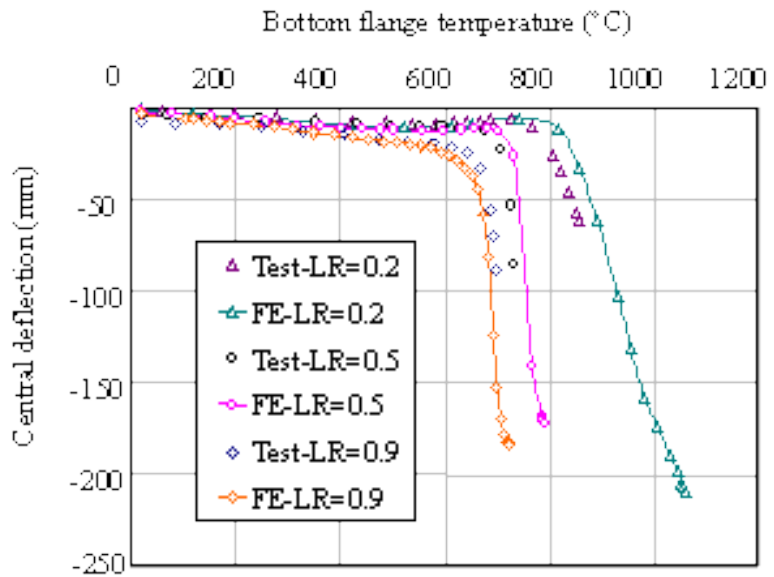

(a) Central deflection.

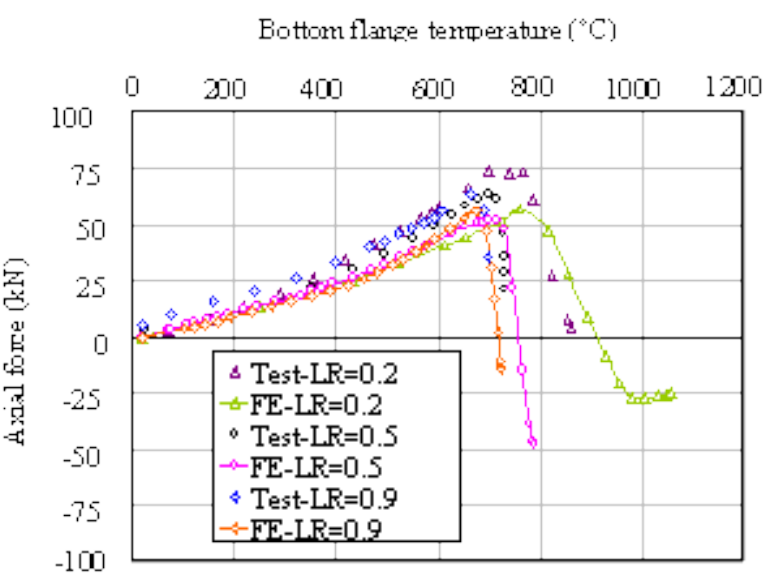

(b) Axial force

Fig. 2 Comparisons between test and predicted central deflection and axial force (end-plate connection, axial stiffness $\mathrm{K}=8 \mathrm{kN} / \mathrm{mm}$ ) for different load ratios.

The end-plate connection was modelled using the appropriate values of rotational stiffness of this type of connection as provided from the experimental tests. Large deflections seen in real structures are often misinterpreted as impending run-away failure. The results from this study suggest that deflections for restrained beams may become much larger than the span/20 or span/30 specified in codes of practice for structural fire testing, and that such levels have nothing to do with run-away. These deflections are largely caused by restrained thermal expansion, and are not a sign of loss of load capacity in the beam. At a later stage catenary action increasingly delays run-away deflection at high temperatures under the effect of the applied load, as axial tension starts to develop, and the beam then acts as a cable hanging from the adjacent cold structure, as shown in Fig. 3.

The question related to the residual axial tensile yield capacity at level of exposure to temperatures associated with the reversal of axial forces from compression to tension was estimated using the reduction factors of the yield strength at elevated temperatures according to BS EN1993-1-2. The residual capacity was estimated to be sufficient for the axial tensile forces to develop at such temperatures. The residual capacity based on the yield stress, not the ultimate stress, was approximately estimated to be in the range of $153 \mathrm{kN}$ to $40 \mathrm{kN}$ for exposure of the test beam to temperatures in the range of $700 \mathrm{C}$ to $1000 \mathrm{C}$. This simple approximate estimation assumes uniform temperature distribution which is conservative. The top flange is usually protected by the nature of the construction system. This indicates that 
Behaviour of Restrained Steel Beam at elevated temperature - Parametric Studies

structural fire design of such beams should include provision for the residual tensile capacity at elevated temperatures to be sufficient for the development of the catenary action.

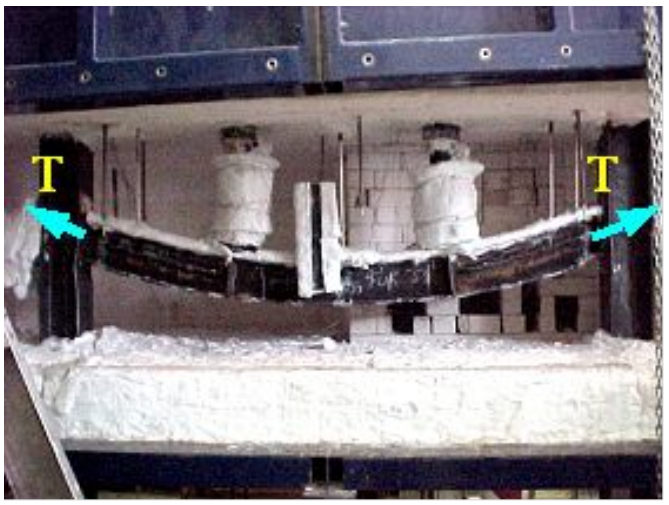

(a) Fire test

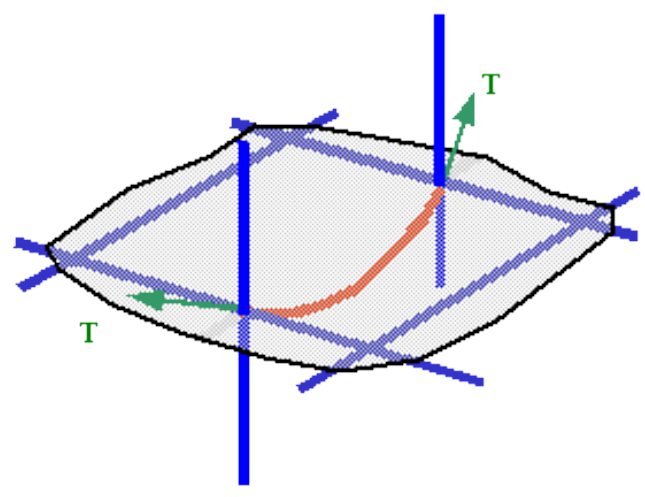

(b) Structure

Fig. 3 Effect of catenary action on heated steel beam at large deflection.

\section{PARAMETRIC STUDIES}

This section describes the investigation of the heated steel beams behaviour as part of a steel frame. It also studies the influence of the catenary action on survival times, taking into account the influence of external restraint. It is noteworthy that the investigation was carried out on non-composite frame, i.e. the contribution of the composite action from the concrete slab was not included.

To understand the various thermal and restraint mechanisms which interact when a restrained steel beam responds to a combination of fire and gravity loads, it is essential to conduct systematic parametric studies that are practically only possible using numerical modelling. VULCAN, the finite element program described previously, has been used to conduct this parametric study, taking into account parameters that influence the structural response at elevated temperatures. These parameters are:

1. Axial restraint

2. Load ratio

3. Beam temperature distribution:

a. Temperature across the beam 
Behaviour of Restrained Steel Beam at elevated temperature - Parametric Studies

b. Temperature profile along the beam

4. Influence of the span/depth ratio

For the purpose of this paper, both parameters namely the Axial restraint and Load ratio are considered and discussed in the following sections. For the purpose of this paper, both parameters namely the axial restraint and Load ratio are considered and discussed in the following sections of the paper. The accuracy of the numerical results has been validated against test results at each stage of the analysis. In addition, further verification can be found in the first author's PhD theses [10]. Conducting such studies enables better understanding of the role of catenary action.

\section{General}

The behaviour of a structure within a fire is significantly influenced by factors such as the rigidity of the connections, the interaction of the structural elements and secondary structural actions. However, true failure certainly does not equate to the prescribed criteria of standard tests. The analysis of steel structures, both individual elements and more complete skeletal frames, in fire is invariably based on a finite element approach. The analysis is typically performed for a sequence of temperatures under constant loads, the principal variant being the material properties, which deteriorate with increasing temperature.

The most apparent aspect of the behaviour in fire is the large deflections of structural members. The state of stress associated with a member subjected to thrust and bending is not unique for a given deflection, and a range of stress states exists depending on the temperature distribution, its material properties and its restraint conditions. Large deflections occur in fire partly because the structural member tries to accommodate the additional length generated by thermal expansion at an early stage of the fire. This is caused by the restraint provided at the ends of the heated beam, making it unable to expand fully. As the temperature increases, the deterioration of the material strength increases. This leads to thermal buckling of the beam element, assisted by the effect of the vertical applied load. Beyond this stage, the beam performs increasingly in tension, using its remaining tensile strength to carry the load by hanging from the edge restraints while the connection sustains the tension force.

It is noteworthy that the effect of the induced axial forces on the local and global buckling were not part of this numerical investigation reported here due to limitations in the FE model. However, the authors recognize this is an important issue in particular at the initial stages of the fire during the development of compression axial forces in the heated steel beam before 
Behaviour of Restrained Steel Beam at elevated temperature - Parametric Studies

large deflections take place resulting in relieving the axial compression. At the time conducting this research, the buckling and post-buckling behaviour including material and geometric non-linearity was investigated by the authors with a FE model capable of taking into accounts such non-linear transient thermo-mechanical effects.

Figure $4 \mathrm{a}, \mathrm{b}$ and $\mathrm{c}$ plot the mid-span deflection, mid-span bending moment and the associated axial force, respectively against the bottom flange temperature of the tested beam (178x102x19kg UB S275) for end-plate beam-to-column connections, without extra axial stiffness, at different load ratios. More details of the test set-up can also be obtained from References 9 and 10.

The figures show the bending strength of the beam decreasing as temperature increases, while the axial tension grows. In Figure 4, the bending moment, approaching zero, starts to change rapidly in the range $700^{\circ} \mathrm{C}-750^{\circ} \mathrm{C}$ for high load ratios, as the axial force in the heated steel beam starts to change from compressive to tensile.

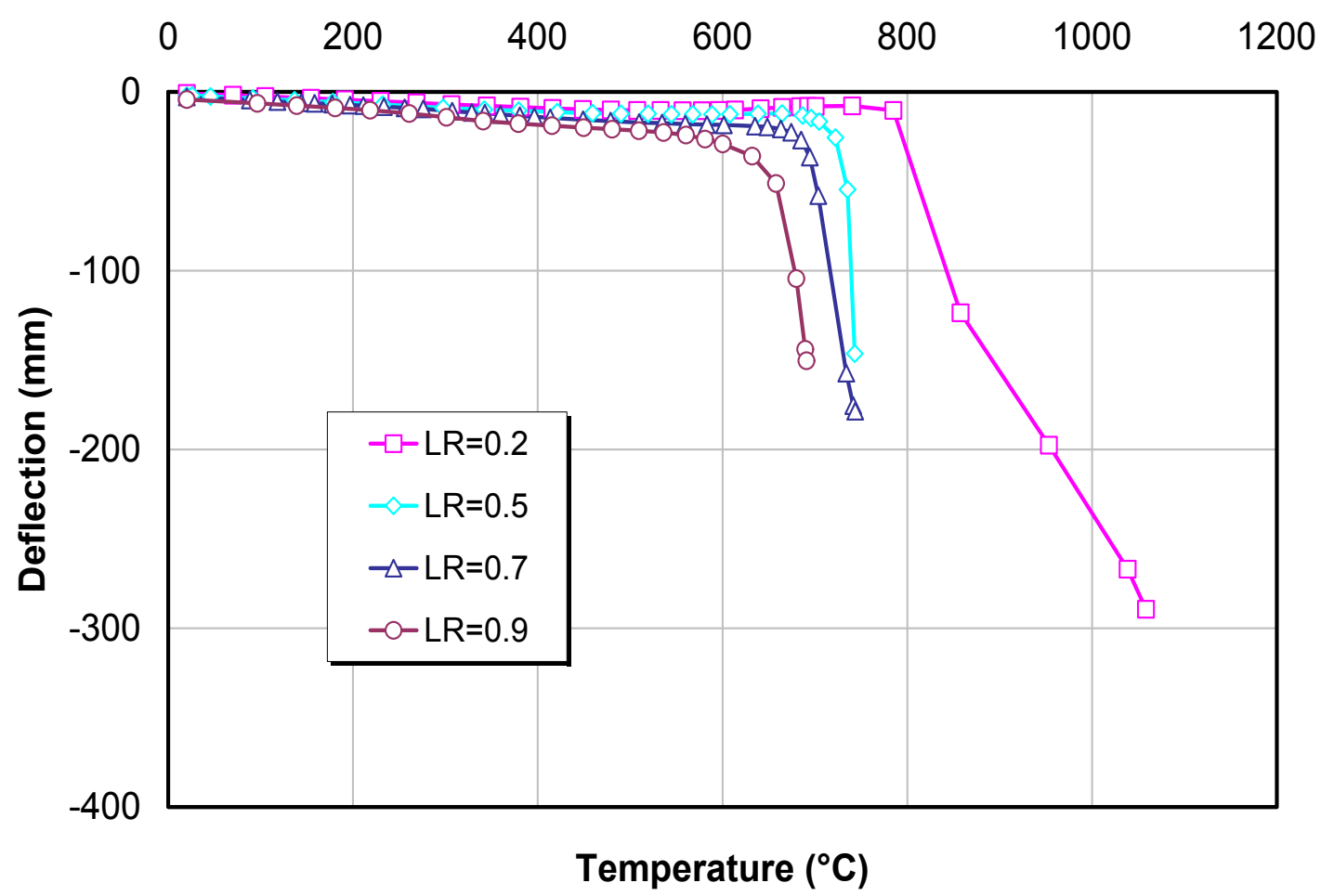

(a). Mid-span deflection 
Behaviour of Restrained Steel Beam at elevated temperature - Parametric Studies

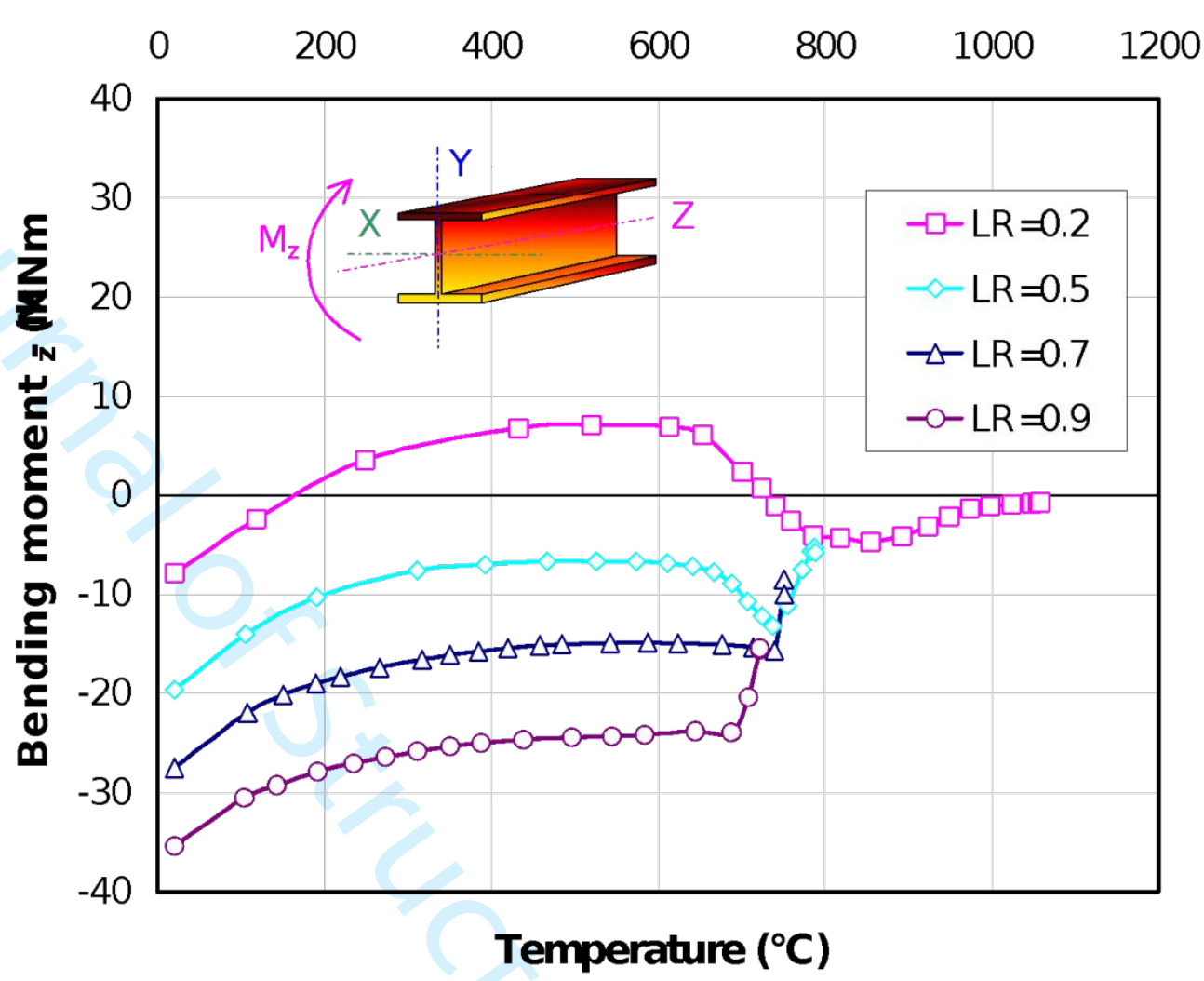

(b). Mid-span bending moment

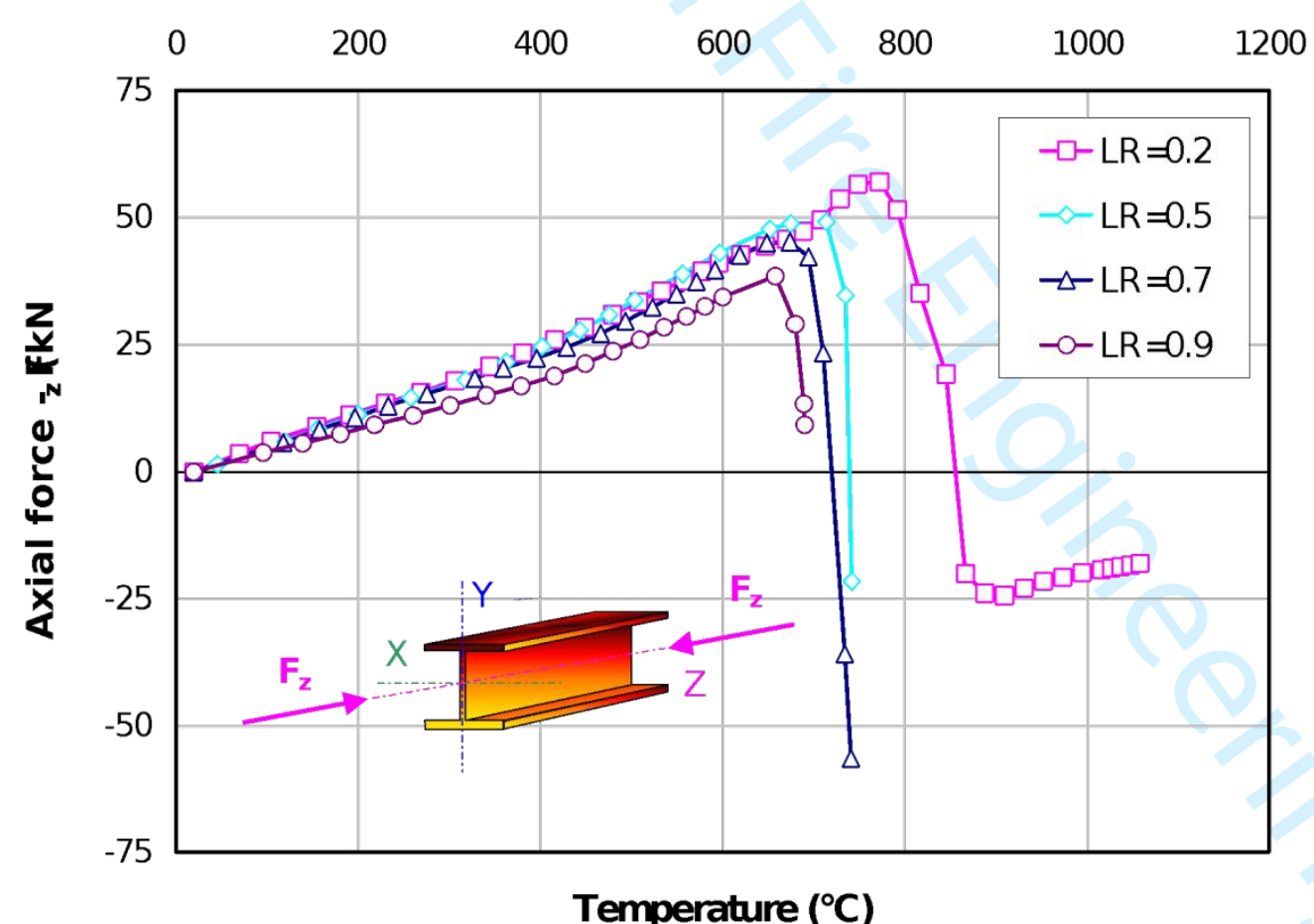

(c). Mid-span axial force

Figure 4. Restraints effects on heated beam at different load levels 
Catenary action starts to take place when the heated steel beam reaches sufficient deflection with enough remaining strength to support itself against the columns. This depends on the degree of protection applied to the beam. However, protecting the top flange of the beam only may provide enough strength to enable it to hang as a cable. This protection could be automatically provided in the case of composite sections whose top flange is embedded in, or placed immediately underneath the concrete slab. The main influence of catenary action appears in the deflection-temperature curves when structures survive up to high deflection. Depending on the load-ratio, the developing tensile force in the beam at large deflection tends to delay the run-away deflection caused by the applied load and material degradation at elevated temperature. It is noteworthy that the study was mainly concerned with the large deflection effects on the behaviour of the heated beam. Due to the nature of the 2-pointloading, the decision was taken to consider the tensile axial force at the point of maximum deflection representing the axial force throughout the limited length of the heated beam for the associated curvature.

In some cases, the computer model showed some numerical instability during the transient coupled thermos-mechanical simulations.

\section{Influence of axial restraints}

Because of the bending stiffness of the columns and mainly because of the axial restraint caused, the beam cannot expand freely along its axis when it is heated. Thus, as a first phase of the fire an axial compressive force develops in the beam and this can influence the stability of the frame. Local buckling, which is not accounted for in this study, can be a result of this phase. Usually this axial expansion phase is followed by a rapid deflection in the heated members until catenary action, with the help of the adjacent structure and the remaining material strength, starts to act to delay run-away deflection.

Figure 5 shows a deflection-temperature comparison of geometrically non-linear thermomechanical transient coupled analyses based on the test temperature data for different levels of additional axial horizontal stiffness $\mathbf{K}$. The analysis is for an end-plate connection, starting with no additional lateral restraint apart from the protected columns, which have a horizontal axial stiffness of $16 \mathrm{kN} / \mathrm{mm}$, with 0.7 load ratio. The maximum axial stiffness that could be applied during the experimental tests was $80 \mathrm{kN} / \mathrm{mm}$. To predict the effect of higher values of additional axial horizontal stiffness, the finite element software VULCAN was used. 
Behaviour of Restrained Steel Beam at elevated temperature - Parametric Studies

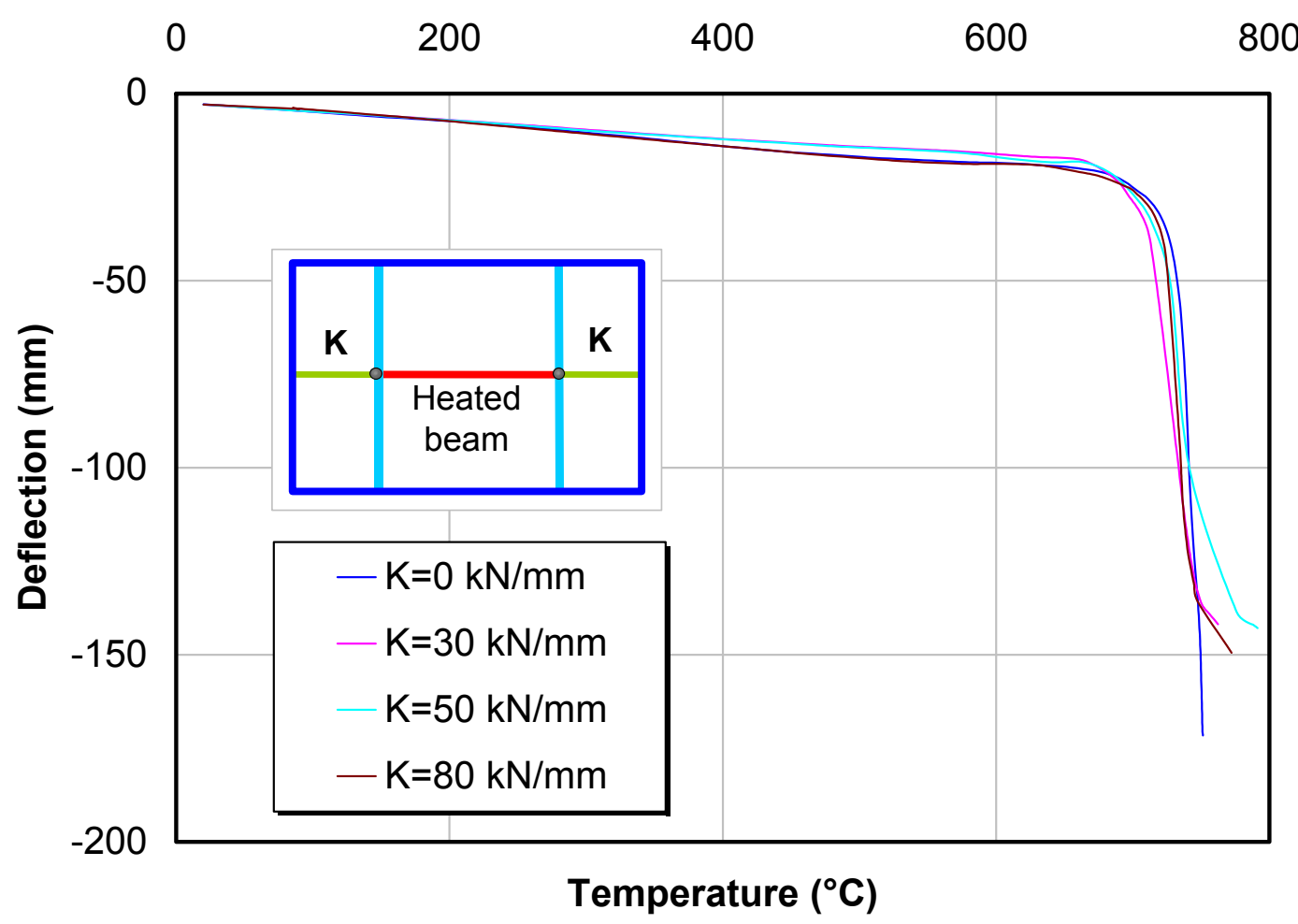

(a). Mid-span deflection at different levels of axial restraint

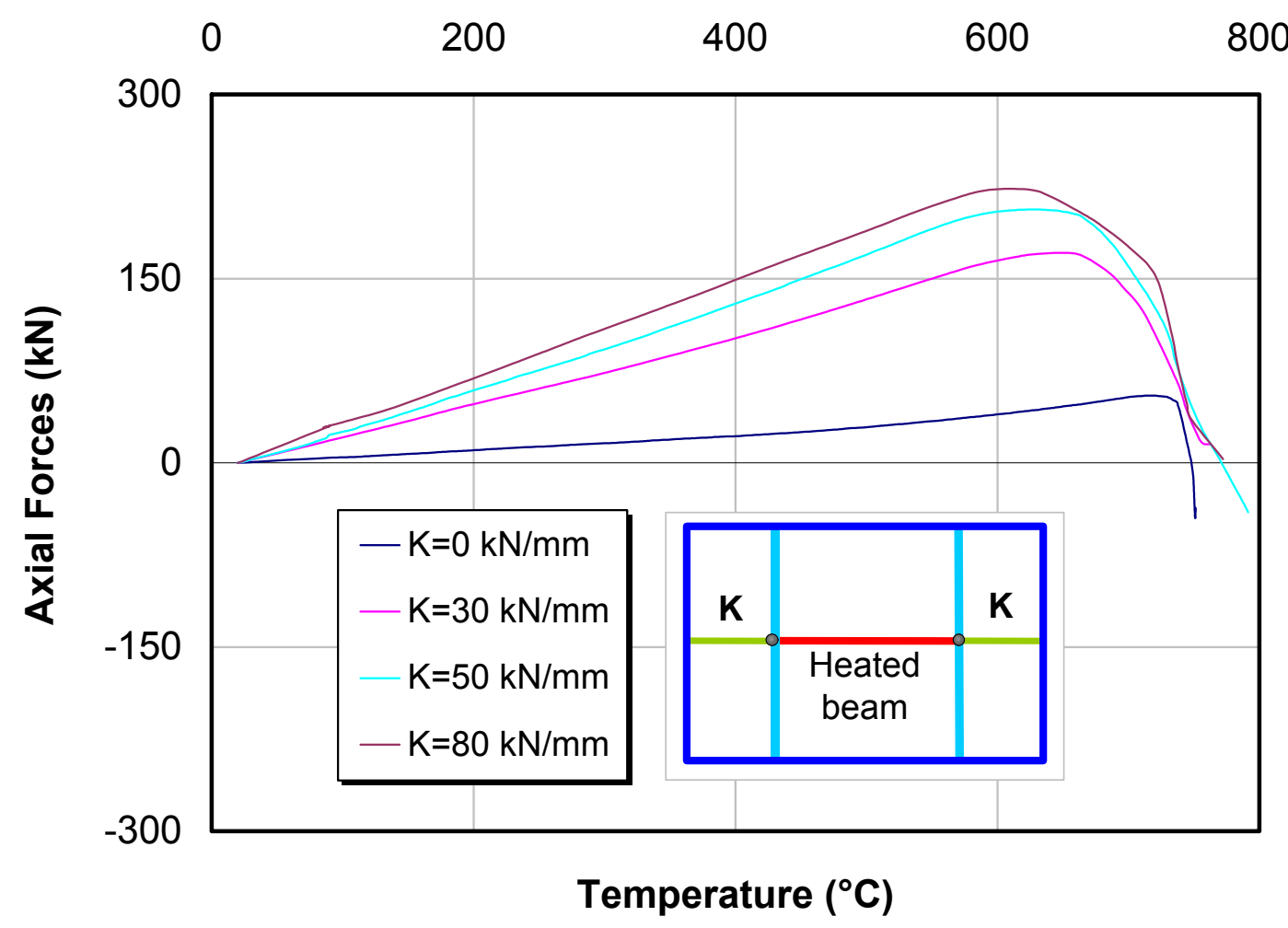

(b). Axial Force at different levels of axial restraint

Figure 5. Behaviour of heated steel beam at different horizontal axial stiffness 
Figure $6 \mathrm{a}$ and $\mathrm{b}$ show the mid-span deflection and the axial force, respectively, in the heated steel beam at different axial horizontal restraint values for end-plate connections with 0.5 load ratio. In Figure 6a, a large horizontal axial stiffness is evidently required to significantly influence the early deflection, and generally the vertical deflection of the beam decreases as the horizontal axial stiffness decreases. This is because the supports, which provide the horizontal stiffness, are able to shift outward upon the expansion of the heated steel beam. However, run-away can occur, even though considerable steel strength remains, because of pulling-in of the supported columns when the flexural stiffness of the beam reduces to a point at which it cannot sustain the imposed load, and there is nothing to restrain the growing deflections [9 and 10]. Further increase in length due to thermal expansion can only be accommodated in further deflection. However, run-away does not occur until much later when the steel bending stiffness is substantially lost at $700{ }^{\circ} \mathrm{C}$. This illustrates that the presence of restraint to end translation delays run-away until higher temperatures, because of development of catenary action to replace the highly depleted flexural stiffness. According to the temperature history during the fire scenario, the remaining material strength may help the heated beam to act in catenary to support the load and tend to stop the run-away.

Figure $6 \mathrm{~b}$ shows that the compressive axial force, during the push-out phase, increases as the axial restraint increases. When the additional axial restraint stiffness is $200 \mathrm{kN} / \mathrm{mm}$, the maximum compressive axial force reaches $300 \mathrm{kN}$ at $500^{\circ} \mathrm{C}$. This value of the axial compressive force drops dramatically to less than $50 \mathrm{kN}$ when the horizontal restraint is only $16 \mathrm{kN} / \mathrm{mm}$, which represents the horizontal restraint provided by the protected columns only. It is evident from Figure $6 \mathrm{a}$ and $\mathrm{b}$ that the rapid increase in central deflection at about $700^{\circ} \mathrm{C}$ is associated with a rapid reduction in the axial compressive forces, developed as a result of the axial restraint of the thermal expansion, It is observed that the diminishing compression force reverses to tension at exposure closer to $800^{\circ} \mathrm{C}$. The changing nature of the axial force is attributed to the development of catenary action at the values of central vertical deflection experienced during fire exposure of such assemblies.

The figure 6 shows that the axial compressive force in the heated steel beam is converted to tensile axial force at around the same temperature of $750^{\circ} \mathrm{C}$ for both cases. 
Behaviour of Restrained Steel Beam at elevated temperature - Parametric Studies

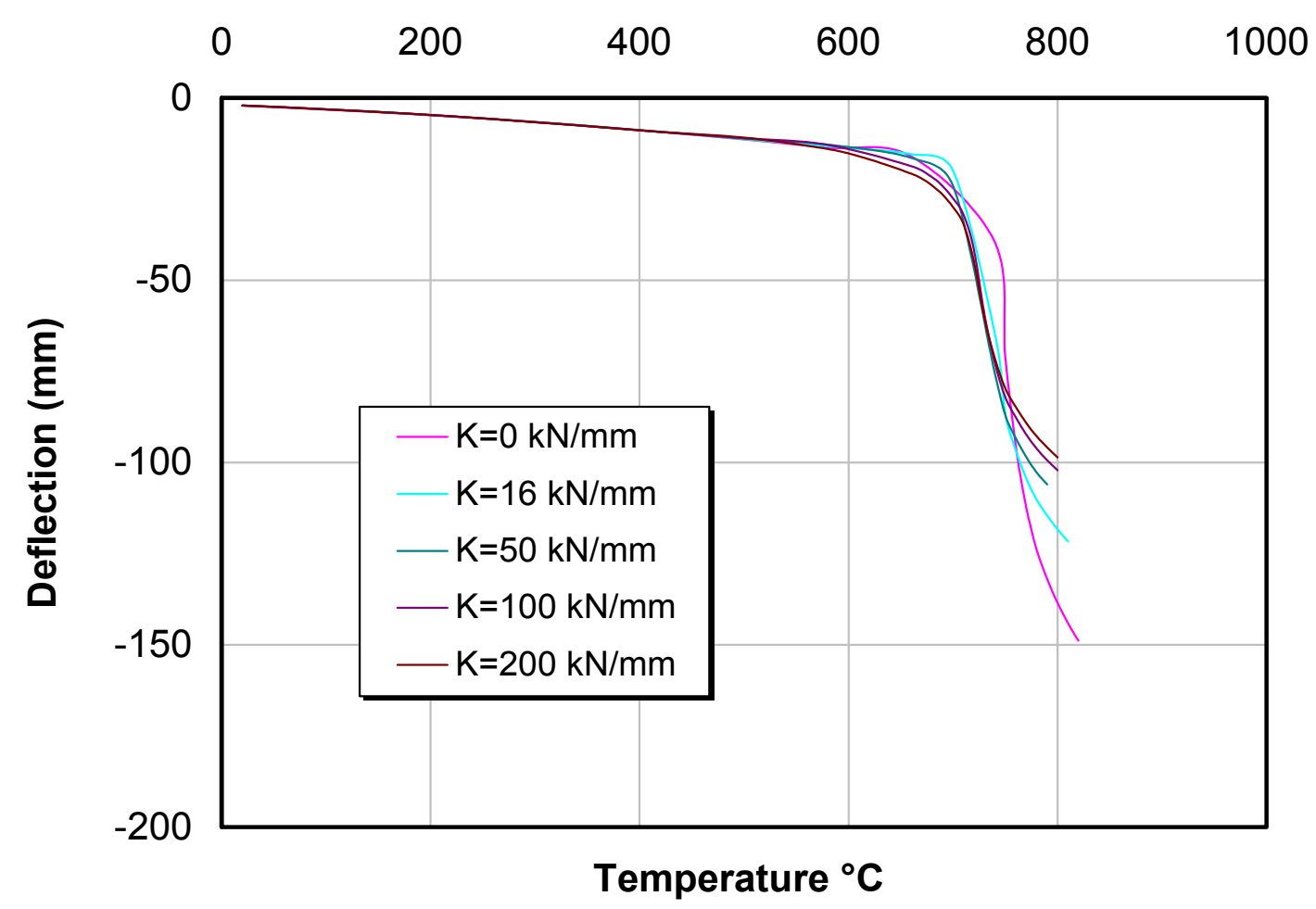

(a). Central deflection

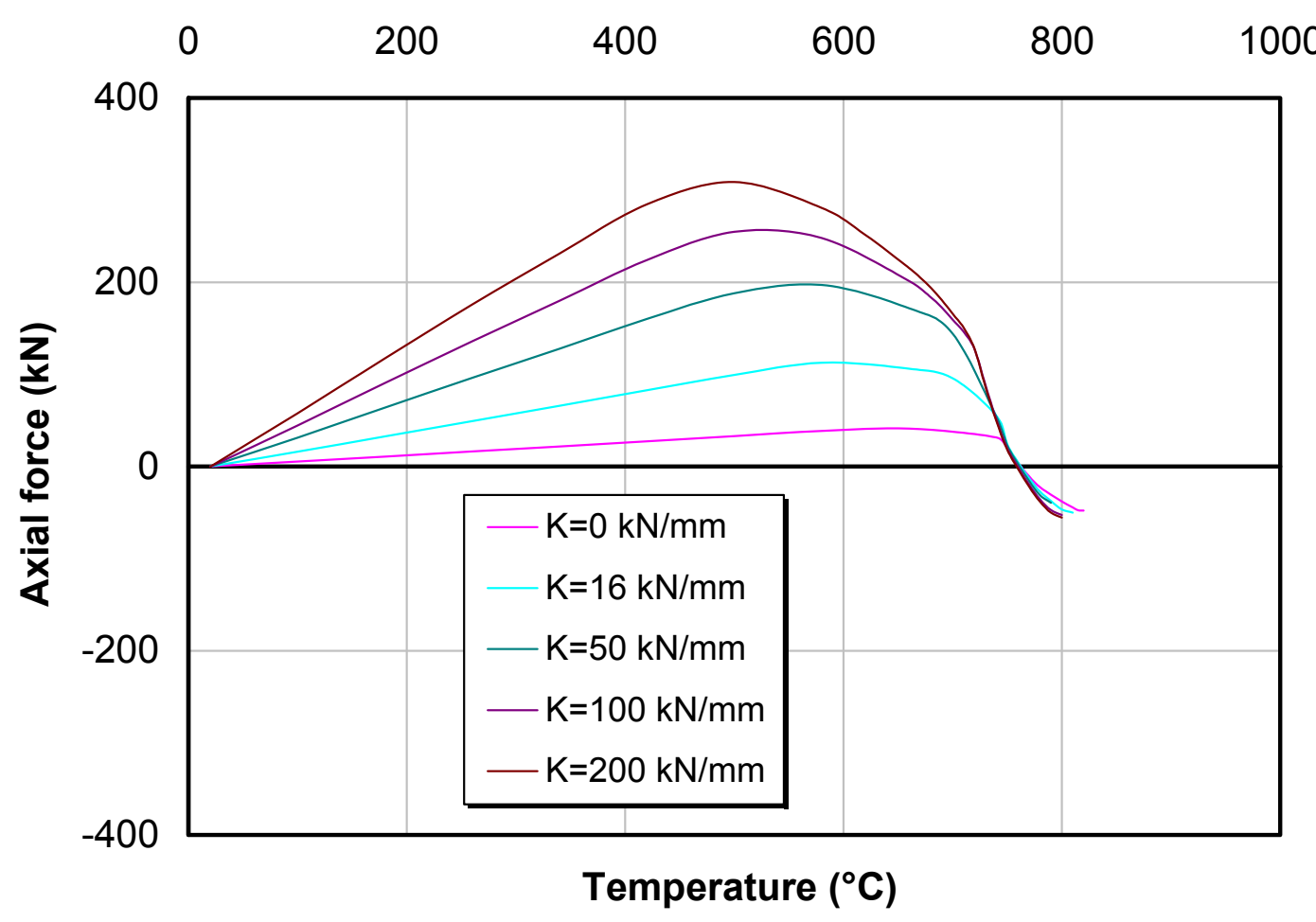

(b). Axial force

Figure 6. Effect of horizontal axial stiffness on the behaviour of the heated steel beam in the test setup 
Behaviour of Restrained Steel Beam at elevated temperature - Parametric Studies

\section{Influence of load-ratio}

BS 5950: Part 8 introduced the 'load ratio' concept to control the failure temperature of a member [12]. This is simply the ratio between the applied load at the time of fire and the load resistance at $20^{\circ} \mathrm{C}$. Once the load ratio is known the limiting temperature value can be obtained from Table 5 of BS 5950: Part 8. The determination of these temperatures was originally based on analysis of a large number of fire resistance tests conducted by SCI [13]. The temperature that the critical element will reach at the end of the specified period of fire resistance, in a test performed according to BS 476: Part 20 is called the Design Temperature. In this section, a number of applied load ratios is considered in order to study the effect of load ratio on a heated steel beam as part of a frame response.

Figure $7 \mathrm{a}$ and $\mathrm{b}$ show the effect of the load ratio for end-plate connections without any additional axial horizontal stiffness, measured against the bottom flange temperature and without any protection applied to the heated beam.

To further appreciate the overall behaviour of the heated steel beam and for simplicity, the analysis assumes a uniform temperature distribution across the steel cross-section aiming to neglect any influence of thermal bowing.

The resulting mid-span deflection with no additional axial stiffness, predicted by VULCAN, is shown in Figure $7 \mathrm{a}$ while Figure $7 \mathrm{~b}$ plots the associated axial force against the bottom flange temperature of the heated steel beam. The beam was loaded by two-point loads applied with jacks which could maintain different load ratios, whilst no axial load was applied to the columns. The results show that the 'failure temperature' of the beam, which is assumed to occur at a limiting beam deflection corresponding to span/20, is found to be insufficient to bring the catenary tension into action. As can be seen, the beam's central deflection within the arrangement can reach higher values than the central deflection of its isolated bare-steel counterpart, specified as span/20. It was noted that increasing the load ratio has a considerable effect in reducing the failure temperature of the beam. Also, it is noted that the load ratios adopted in the analysis are reasonable to represent a wide range of load ratios, which would be expected to exist in typical structures. 
Behaviour of Restrained Steel Beam at elevated temperature - Parametric Studies

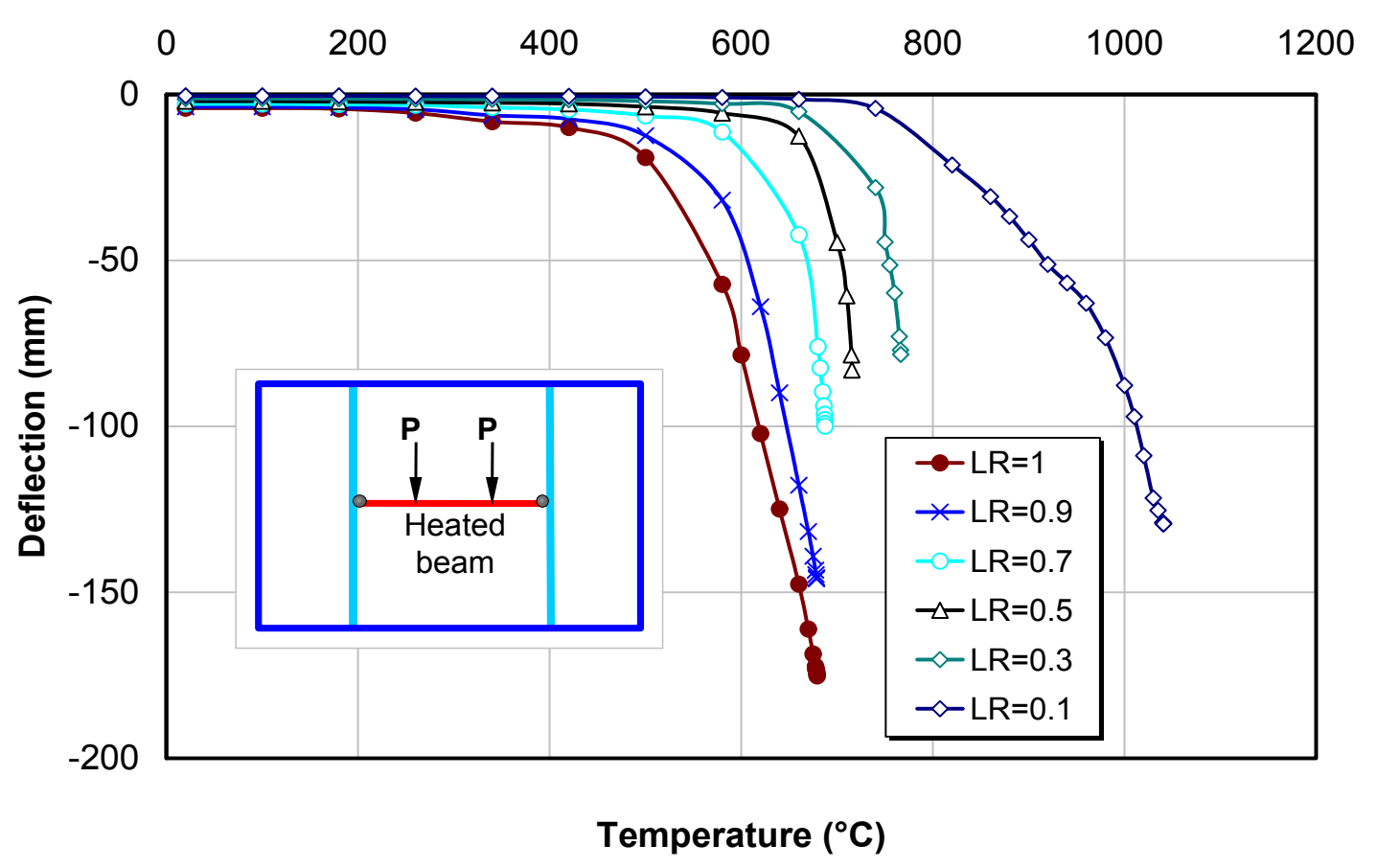

(a). Central deflection

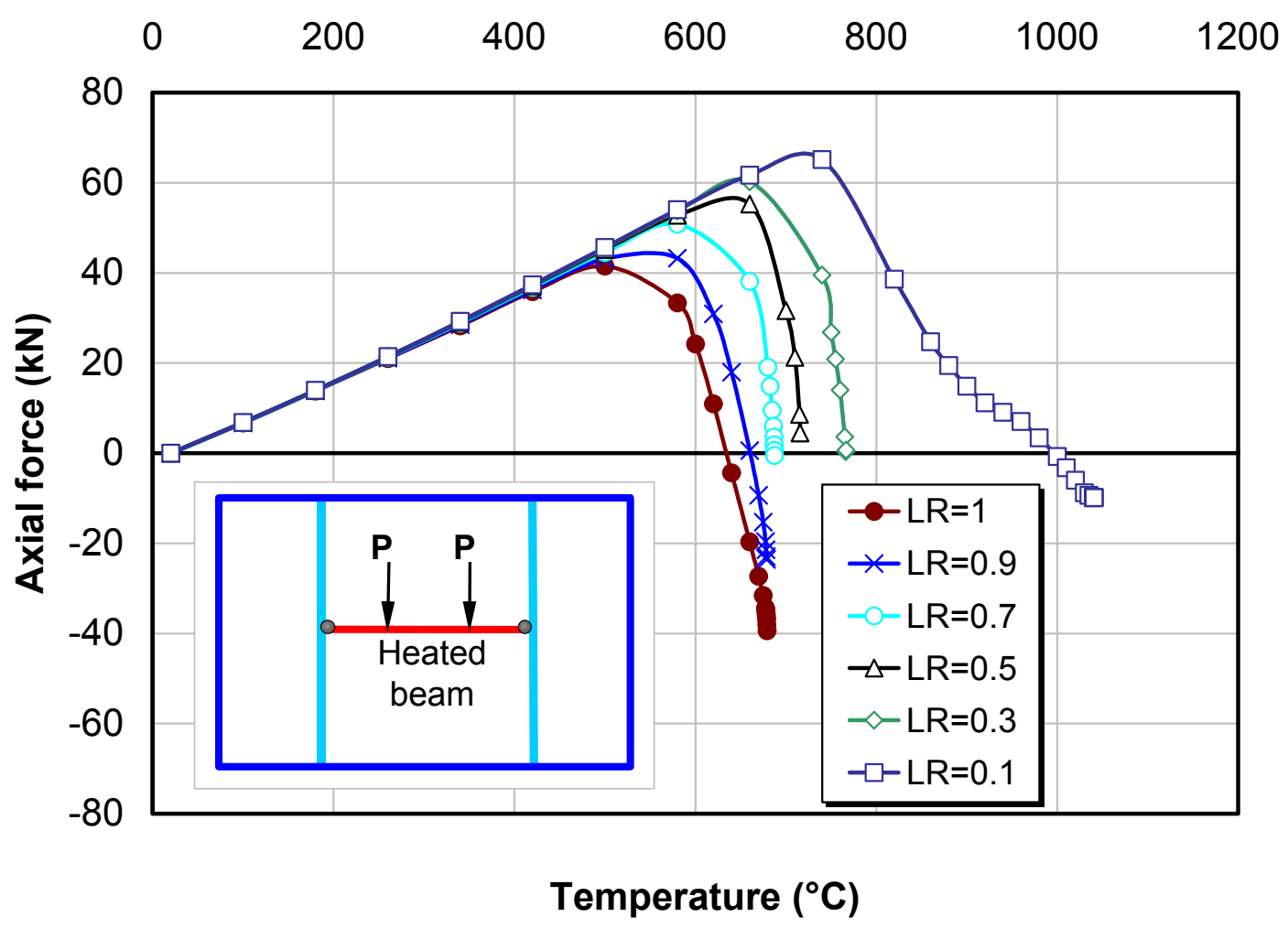

(b). Axial force

Figure 7. Effect of the load ratio $-\mathrm{K}=0 \mathrm{kN} / \mathrm{mm}$ 
In these analyses, the beam was assumed to be unprotected and uniformly heated. As a result of this, the steel beam is expected to have low material strength at high temperature. This reduces the effect of the tension at high deflection, in helping the beam to hang from the adjacent structure. For temperatures beyond $600^{\circ} \mathrm{C}$, the bare-steel beam undergoes a higher deflection rate compared to the beam within the composite arrangement. At a deflection of $175 \mathrm{~mm}$ for a beam with $100 \%$ load ratio, the failure temperature of the beam within the arrangement was found to be around $690^{\circ} \mathrm{C}$. However, at a deflection of $130 \mathrm{~mm}$ for $10 \%$ load ratio, a temperature of $1150^{\circ} \mathrm{C}$ was reached. This represents a considerable increase of capacity compared to the deflection limit of span/20.

Figure 8 shows the effect of the load ratio for the end-plate connection with additional axial horizontal stiffness, plotted against the bottom flange temperature. The analysis was carried out without any protection to the top flange to maintain uniform temperature distribution across the cross-section of the tested beam. The results show that load ratio has a great influence on the beam response at elevated temperature during the catenary action at large deflection. The existence of the axial horizontal stiffness helps the beam to recover from runaway when the material degrades; however, this behaviour is emphasised at low load ratio.

Another set of analysis were conducted to investigate the effect of the protection that could be provided to the top flange of the heated beam by the concrete slab. It is noteworthy that the additional structural resistance provided by the slab was neglected in the modelling efforts reported in this paper and not presented in the fire testing set-up. Figure 9 shows the effect of the load ratio for the end-plate connection with $20 \mathrm{kN} / \mathrm{mm}$ additional axial horizontal stiffness, plotted against the bottom flange temperature. Figure 9a shows the temperature scheme adopted along the heated beam. The analysis was carried out with $50 \%$ protection to the top flange of the tested beam. The results show that load ratio has a great influence on the beam response at elevated temperature during the catenary action at large deflection. Clearly the existence of the axial horizontal stiffness helps the beam to recover from run-away when the material degrades; however this behaviour is emphasised at low load ratio. 
Behaviour of Restrained Steel Beam at elevated temperature - Parametric Studies

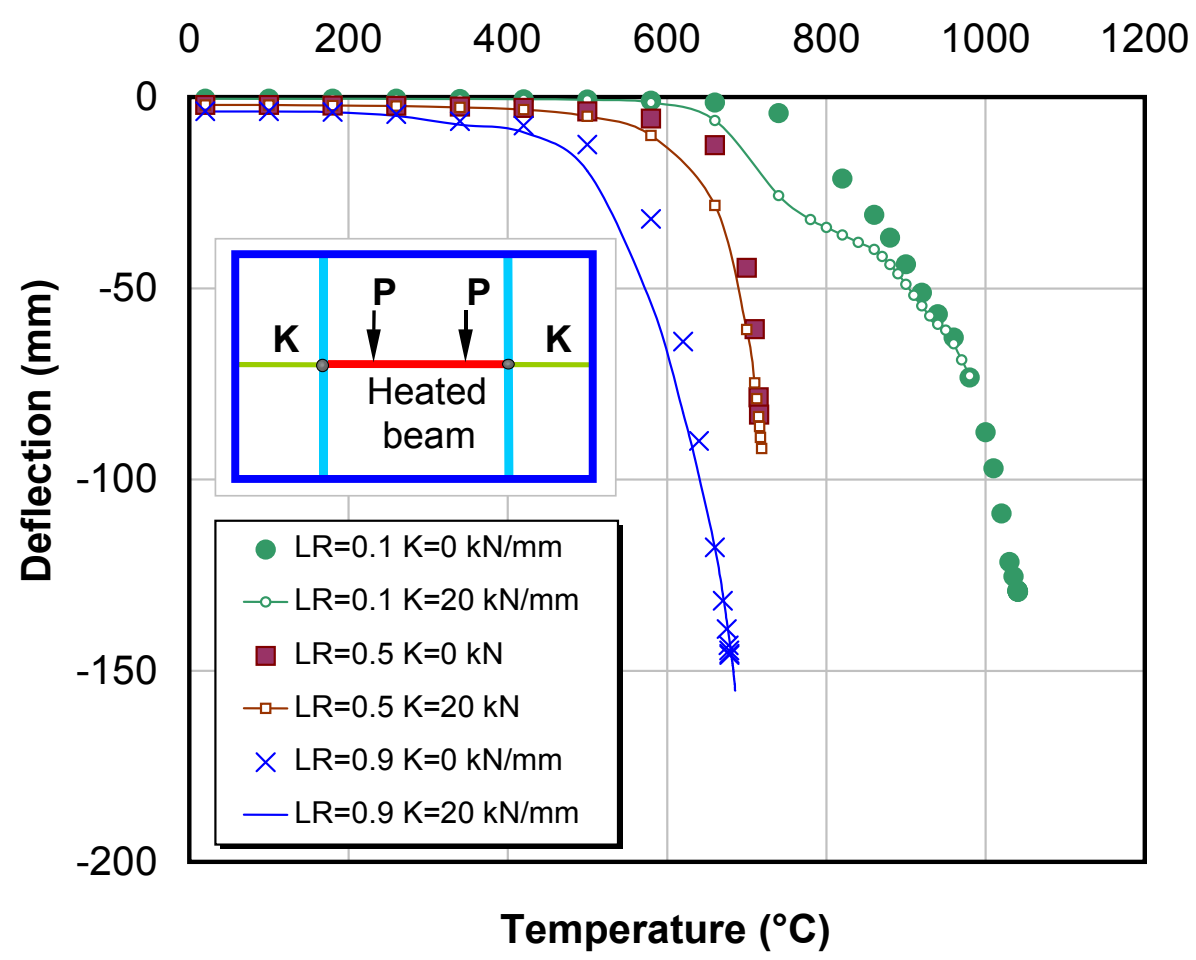

(a). Central deflection

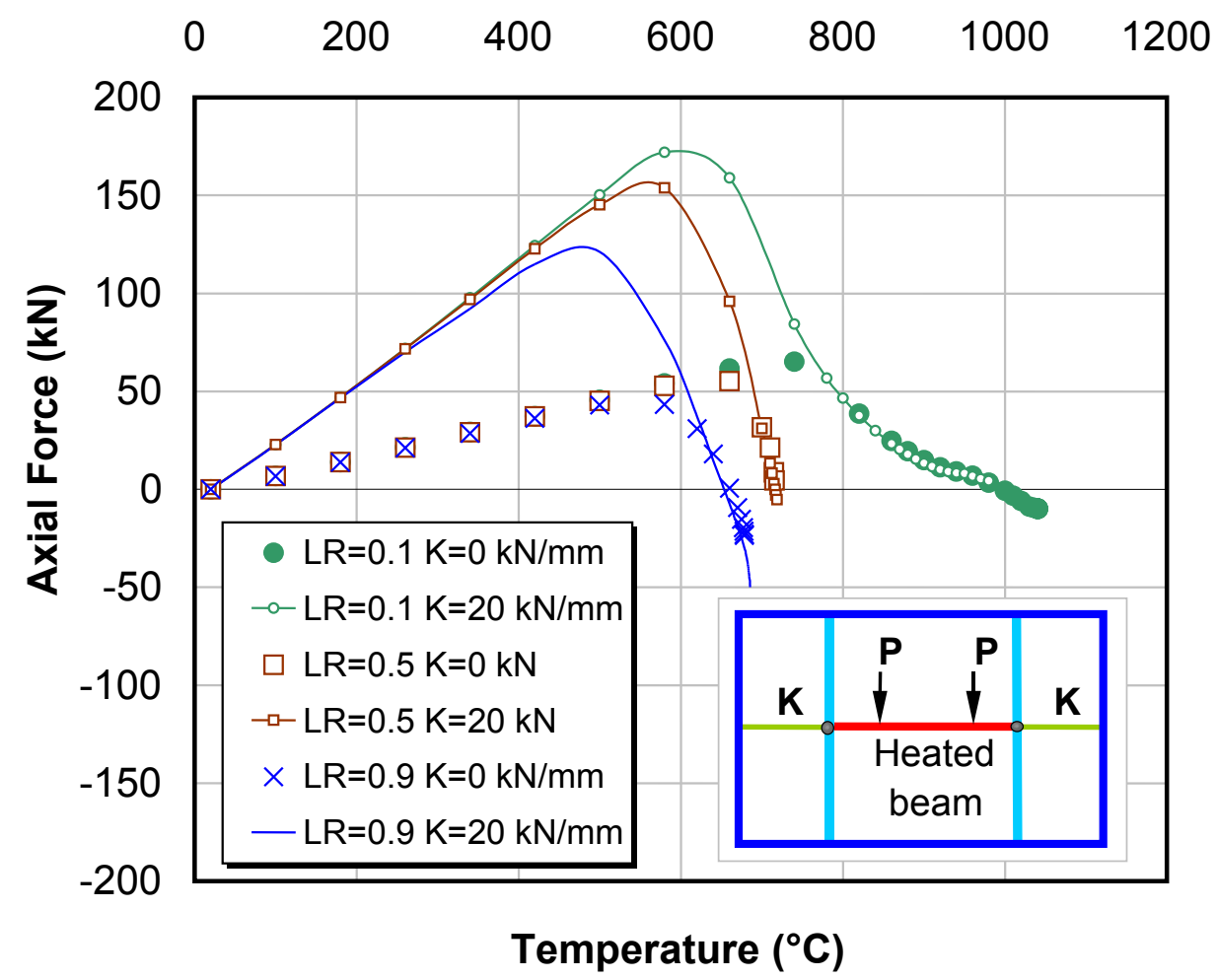

(b). Axial force

Figure 8. Effect of the load ratio - Comparison for different additional stiffnesses 
Behaviour of Restrained Steel Beam at elevated temperature - Parametric Studies

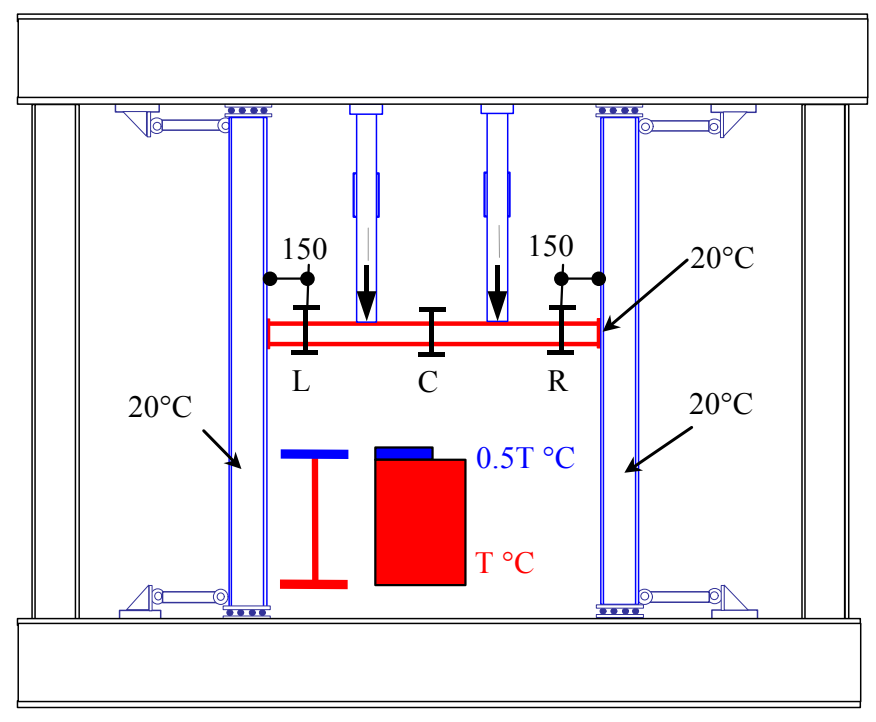

(a). Temperature distribution

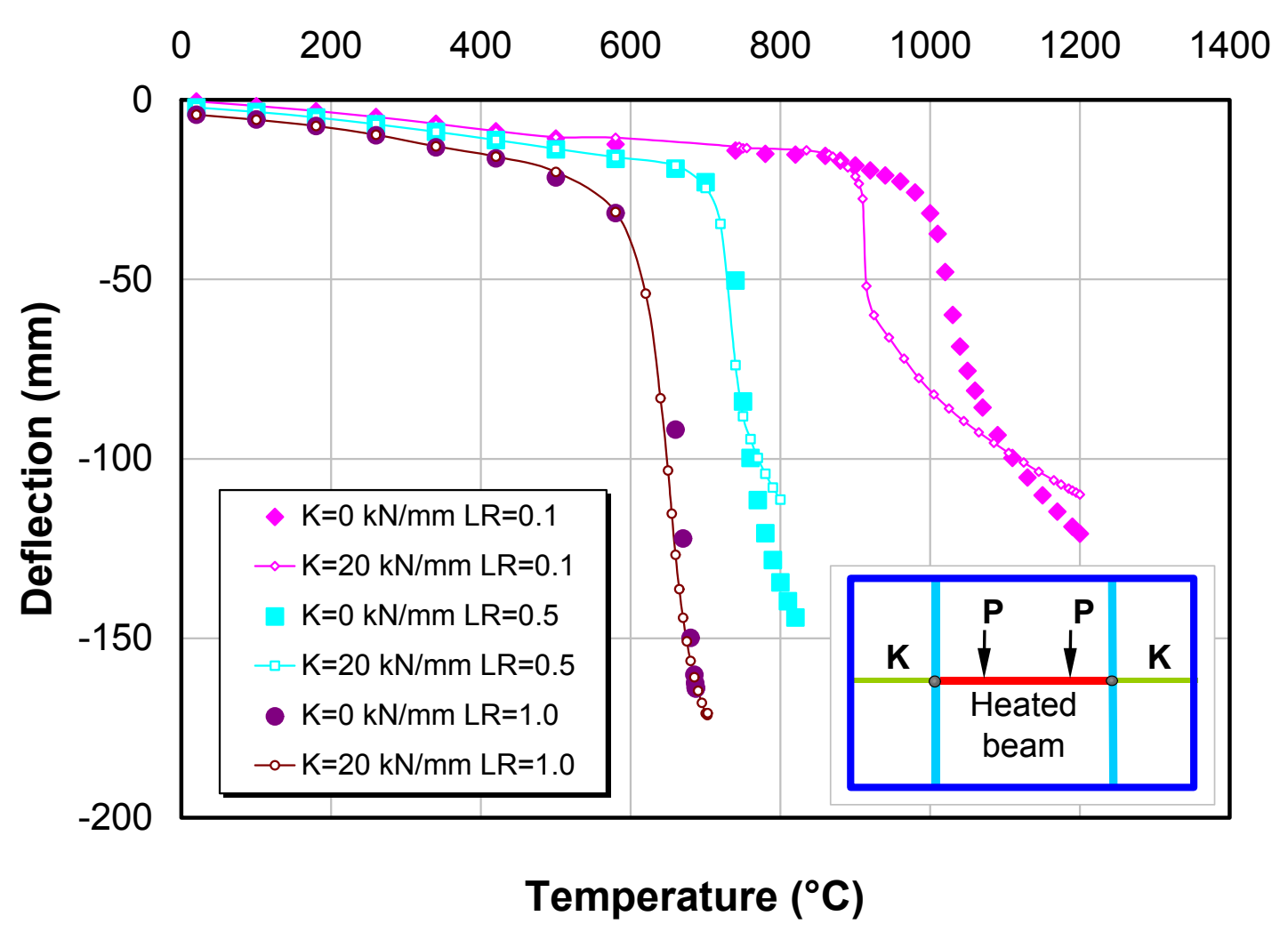

(b). Central deflection 
Behaviour of Restrained Steel Beam at elevated temperature - Parametric Studies

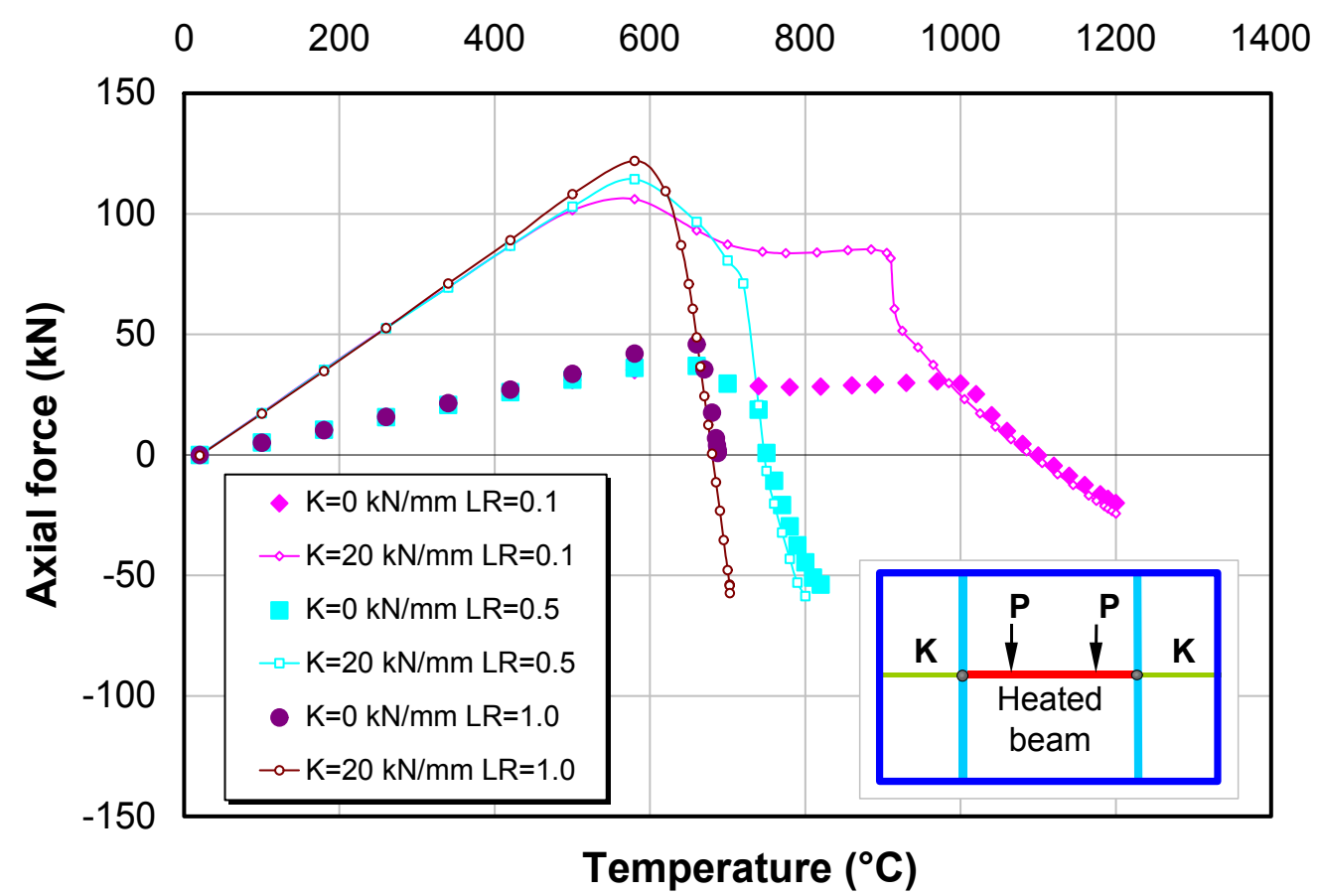

(c). Axial force

Figure 9. Effect of load ratio - with protected top flange

The behaviour of the heated steel beam comprises a two-stage response, as described earlier. There is initial push-out caused by the compressive force until the tensile force starts to develop, causing the catenary action which results in considerable enhancement of the behaviour of the heated steel beam at large deflection. Therefore, it is necessary to take into account the whole response of heated beam when considering the frame response at elevated temperature. This should also be taken into consideration when developing mathematical models for estimating the behaviour of steel beams in fire.

\section{CONCLUSIONS}

Parametric studies have been conducted to investigate the effect of catenary action on heated steel beams, as part of frame response in fire. Analyses were carried out using a validated finite element program VULCAN that was broadly validated against experimental data at each development stage $[10,11]$. The numerical model showed the ability to simulate, with good agreement, the structural behaviour of the steel frame tested at Manchester University. The behaviour of the frame is well predicted up to the point where the tests were stopped, 
except for the local buckling of the beam which occurred at some stages during the tests which cannot be modelled using the beam-column element currently implemented in VULCAN. The computer model has been used to highlight the influence of several physical parameters on the behaviour of the test frame, and the following conclusions could be drawn:

- The behaviour of the column and beam considered as separate members (i.e. no composite action) during the fire is different from the behaviour of the frame as a whole. The fire resistance of the beam as the weakest member is considerably less than the fire resistance of the complete frame.

- Catenary action occurs, and affects the heated beam by delaying run-away deflection at high temperature under the effect of the applied load. This occurs when the tensile axial force starts to develop at high deflection, helping the beam to act as a cable hanging from the adjacent cold structure. This factor has no sign of existence in any of the calculation methods for the steel member in fire. In the results reported here, axial tensile force develops at high temperature and large deflection. Depending on the other factors such as axial horizontal restraints level and the load ratio, the catenary action will be developed in the heated steel beam which results in slowing the deflection. In this study, evidence is provided indicating the role that the catenary action can play in terms of survival time for a steel beam in fire, raising the question of reviewing these calculation methods to include its effect.

- Variation of the horizontal end-restraint level has a major effect on the behaviour of the beam at high deflection, and the loading on a beam at large displacement can be carried very effectively by catenary behaviour. An increase of axial horizontal stiffness helps the catenary action to prevent run-away at lower deflections. The studies also investigated the influence of varying the load ratio on the behaviour of the heated beam at large deflection, and how it affects the efficacy of the catenary action. The study suggests that care should be taken when selecting the load ratio to be used in the design.

- Large deflections seen in real structures are often misrepresented as impending run-away failure. The results in this study clearly show that the deflections of a restrained beam can be much larger than those for simply supported beam, but they have nothing to do with run-away. These deflections are caused almost entirely by the increased length of the beam through thermal expansion. They are not a sign of loss in the strength or stiffness of the beam until the late stage when the catenary action starts to delay the run-away. 
Behaviour of Restrained Steel Beam at elevated temperature - Parametric Studies

\section{REFERENCE}

[1]. Allam, A., Burgess, I., Plank, R., "Fire Modelling of the Queensberry House Project", Research Report DCSE/96/F/5, University of Sheffield, UK, 1996.

[2]. Peijun Wang, Changbin Liu, Mei Liu, Xudong Wang "Numerical studies on large deflection behaviour of axially restrained corrugated web steel beams at elevated temperatures", Thin-Walled Structures - Volume 98, Part A, January 2016, Pages 58-74

[3]. Peijun Wang, Ning Ma, Xudong Wang "Numerical Studies on Large Deflection Behaviours of Restrained Castellated Steel Beams in a Fire”, Journal of Constructional Steel Research 100 (2014) 136-145

[4]. Wang Y C. "Steel and Composite Structures, Behaviour and Design for Fire Safety. Spon Press; 2002.

[5]. Wang Y C. "Performance of Steel-Concrete Composite Structures in Fire. Prog Struct Eng Mater 2005; 7(2): 86-102.

[6]. Ahmed Allam, Ian Burgess, Roger Plank, "Performance-Based Simplified Model for a Steel Beam at Large Deflection in Fire", 4th International Conference on PerformanceBased Codes \& Fire Safety Design Methods - Melbourne, Australia March 20-22, 2002 .

[7]. M. M. S. Dwaikat, V. K. R. Kodur "A Performance Based Methodology for Fire Design of Restrained Steel Beams”, Journal of Constructional Steel Research 67 (2011) 510524

[8]. Allam, A. M., Green, M. G., Burgess, I. W., and Plank, R. J., "Fire Engineering Design of Steel-Framed Structures-Integration of Design and Research", Journal of Construction Steel Research, Vol. 46, paper number 170, 1998.

[9]. T.C.H, Fahad, M.K., Liu, Davies, J.M., "Experimental investigation of behaviour of axially restrained steel beams in fire", Journal of Constructional Steel Research 58 (2002) 1211-1230.

[10]. Ahmed Allam, "The Large-deflection Behaviour of Structural Frames in Fire", $\mathrm{PhD}$ thesis, Department of Civil and Structural Engineering, University of Sheffield, Feb 2003. 
Behaviour of Restrained Steel Beam at elevated temperature - Parametric Studies

[11]. Spyros Spyrou "A component model for steel end-plate connections in fire", Phd thesis, Department of Civil and Structural Engineering, University of Sheffield, 2001

[12]. "BS 5950 Structural Use of Steelwork in Building: Part 8: Code of Practice for Fire Resistance Design “, British Standard Institution, London, 1990.

[13]. Newman, G. M., “An Introduction to the Calculated Performance of Steel Structures in Fire", Steel Construction Today, No. 4, 1990, pp. 68-70 